\title{
DESEMPENHO DO ACADÊMICO DO CURSO DE BIBLIOTECONOMIA DA UNIVERSIDADE ESTADUAL DE LONDRINA
}

\author{
Linete Bartalo ${ }^{1}$
}

BARTALO, Linete. Desempenho do acadêmico do curso de biblioteconomia da Universidade Estadual de Londrina. Semina: Ci. Soc./Hum. Londrina, v. 16. n. 2., p. 27-35, out. 1995.

RESUMO: Estudo desenvolvido junto ao curso de Biblioteconomia da Universidade Estadual de Londrina, que investigou através da metodologia da problematização, os fatores: demanda ao curso, aprovação no concurso vestibular, remanescentes de outros cursos que ingressaram no curso de Biblioteconomia, desempenho acadêmico, percepção do corpo discente quanto ao curso e do corpo docente quanto ao desempenho acadêmico, nos três últimos anos. Analisa os dados e aponta hipóteses de solução no sentido de que se realize estudos mais abrangentes de avaliação do curso, bem como a divulgação da profissão bibliotecária e a agilização de programas que contemplem a discussão das dificuldades encontradas na formação profissional e que conseqüentemente se refletem no desempenho acadêmico. Ressalta a necessidade de uma disciplina voltada para a leitura que deve ser implantada no currículo, não só do curso de Biblioteconomia, como também em outros cursos da Universidade, uma vez que a capacidade de leitura critica foi fator apontado como preponderante na formação profissional. Prevê a possibilidade de aplicação imediata das hipóteses de solução levantadas.

PALAVRAS-CHAVE: Biblioteconomia - desempenho acadêmico; formação acadêmica; perfil discente

\section{INTRODUÇÃO}

O curso de Biblioteconomia da Universidade Estadual de Londrina-UEL foi implantado em 1973 e reconhecido em 27/09/76 pelo Decreto Federal 78.469 , com turno matutino, com quarenta vagas semestrais e três anos de duração.

Em 1977 passou a ser ofertado no turno noturno com três anos e meio de duração e 40 vagas.

Até 1984 sofreu duas reformulações de currículo no sentido de adequar a formação do profissional bibliotecário às necessidades do mercado de trabalho e atender as exigências do Conselho Federal de Educação que procedeu a reestruturação do currículo mínimo em vigor, tendo seu tempo médio de duração aumentado para quatro anos e com aulas aos sábados.

Em 1985 e 1987, o currículo sofreu novas alterações para corrigir distorções e modificar alocação de disciplinas, pré-requisitos e ementas.

Em 1992, com a implantação do regime seriado anual, voltou a ser ofertado no turno matutino com quarenta vagas, tendo seu currículo reformulado novamente.

\section{PROBLEMA}

Desde a implantação do curso de Biblioteconomia na UEL, o baixo desempenho dos alunos, a alta taxa de evasão, a grande incidência de reprovação, a diminuição da demanda para o curso, a demora do aluno em conclui-lo, caracterizando a retenção (quando por qualquer motivo, o aluno não tem condiçōes de concluir o curso dentro do tempo médio de duração do mesmo) tendo muitas vezes que prestar outro concurso vestibular para não jubilar, constitui-se preocupação constante por parte do corpo docente.

O desempenho no mercado de trabalho, do profissional formado nestas condições, passa a ser também preocupação do Departamento, que é responsável por esta formação.

Refletindo sobre isto com base na obsenvação enquanto acadêmica do referido curso, e hoje, como docente do departamento e acreditando que a solução do problema encontra-se no próprio ambiente onde ele ocorre, ainda que não seja uma solução completa, mas pelo menos o desencadeamento para formas mais adequadas de solução, interessei-me em estudar o problema, partindo da seguinte questão: "Como transformar a clientela que chega para o curso de Biblioteconomia em discentes motivados, sensibilizados com os problemas profissionais, envolvidos com a qualidade da sua formação e conseqüentemente profissionais competentes?"

Esta questão estudada provavelmente conduzirá a uma forma de reverter a situação colocada, senão totalmente, pelo menos abrindo caminho para maneiras mais adequadas de encaminhamento da busca de soluçōes.

Nesta busca pode-se formular um estudo inicial do problema da seguinte forma: "Como se caracteriza,

1 - Departamento de Biblioteconomia/Centro de Educação, Comunicação e Artes/Universidade Estadual de Londrina, Caixa posłal 6001. Londrina, PR., Brasil, CEP 86051-970.

Semina: Ci. Soc./Hum. v. 16., n. 2. Ed. Especial. p. 27-35. out. 1995 
qualitativamente, o desempenho acadêmico dos alunos do curso de Biblioteconomia e que repercussões isso tem na sua formação profissional?

Alguns fatores podem ser apontados como hipóteses de causas mais imediatas para a situação colocada. São elas:

- O curso de Biblióteconomia é de fácil ingresso, um dos menos procurados (no último vestibular, foi o curso que apresentou a menor relação candidato/vaga entre os cursos da UEL);

-Por apresentar muitas vagas e receber muitos alunos remanescentes, o corpo discente é desmotivado;

- Existe desconhecimento por parte da população, das atividades que o profissional bibliotecário pode desempenhar e por conseguinte, dos remanescentes e até mesmo dos vestibulandos do próprio curso;

-As atividades do bibliotecário no mercado de trabaIho, geralmente são desempenhadas por pessoas sem formação acadêmica;

- A classe dos bibliotecários não é unida e isso se reflete nos alunos;

$O$ contexto onde esta situação está inserida também afeta o seu agravamento, oferecendo os determinantes maiores do problema, que se situam a nivel nacional, no que diz respeito aos valores que o povo atribui à sua nação, à sua história, tradições político-sociais, que podem ser assim traduzidas:

-Desvalorização da cultura a nível nacional;

-Desprezo aos documentos que fazem parte da memória nacional;

-Conseqüente desvalorização da profissão bibliotecária, cuja matéria prima de trabalho é o conhecimento produzido e acumulado pela humanidade.

Em função da desvalorização da profissão, o curso, além de desvalorizado, passa a ser discriminado e seu corpo docente e principalmente discente, estigmatizado junto à comunidade universitária, a ponto de gerar desânimo e desmotivação do aluno para com o curso.

Para encaminhamento dos estudos que conduzam à solução do problema, selecionou-se algumas estratégias, quais sejam, levantamento de dados, sondagem de opiniões, revisão de literatura, entre outras, incidindo sobre os pontos chave destacados, visando analisar a realidade e propor soluções.

\section{PONTOS CHAVE}

-Número de candidatos ao curso de Biblioteconomia nos três últimos anos versus número de vagas ofertadas;

- Candidatos ao curso de bibilioteconomia aprovados;

- Vestibulandos ao curso de biblioteconomia aprovados, que efetivaram a matricula;

-Desempenho obtido pelos alunos dos três últimos anos nas provas de Português, Redação e Estudos Sociais ,cujos pesos são maiores para a área de ciências humanas, onde está alocado o curso de Biblioteconomia;

-Quantidade de alunos que ingressaram no curso de Biblioteconomia como remanescentes e de que outros cursos eles são provenientes versus quantidade de alunos que prestaram vestibular para o curso de Biblioteconomia;

-Desempenho acadêmico dos alunos que entraram nos três últimos anos, no curso de Biblioteconomia;
-Percepção dos alunos que entraram nos três últimos vestibulares em relação ao curso;

-Percepção dos professores quanto ao desempenho dos alunos.

\section{TEORIZAÇÃO}

A busca de dados seguiu os pontos chave destacados, tendo sido contatada a Coordenadoria de Assuntos de Ensino de Graduação-CAE da UEL, informalmente para alguns dados e oficialmente para outros, no que diz respeito aos seis primeiros aspectos. Quanto aos dois últimos, percepção dos alunos quanto ao curso e dos professores quanto ao desempenho dos alunos, foram elaborados questionários, que constituíram-se em instrumentos para investigação destes fatores. Os dados foram tabulados manualmente e aqueles colhidos nas questões abertas foram registrados e analisados.

Além disso, buscou-se literatura a respeito do curso de Biblioteconomia da UEL, de estudos semelhantes realizados em outras Instituições que oferecem o curso de Biblioteconomia, sobre os exames vestibulares sobre a formação do profissional bibliotecário e suas dificuldades.

Em 1992 foi implantado o regime seriado anual na Universidade Estadual de Londrina, sendo que a partir de então trabalha-se com os dois regimes acadêmicos simultaneamente, este e o antigo regime de créditos por disciplina semestral, até que este último se extingüa. Considerando-se a possível aplicação das soluções que este estudo apontar à realidade estuda$\mathrm{da}$, achou-se por bem delimitar o universo de estudo aos alunos que ingressaram a partir da implantação do novo regime acadêmico.

O Quadro 1 mostra como foram compostas as turmas do curso de Biblioteconomia nos três últimos anos: QUADRO 1

Composição das turmas do Curso de Biblioteconomia da UEL de 1992 a 1994

\begin{tabular}{c|c|c|c|c|c|c|c|c}
\hline Ano & Vg & Ineo. & CN & Apr & Mat & Pom & PD & Tot \\
\hline 1992 & 40 & 28 & 0,70 & 12 & 9 & 24 & $\cdot$ & 33 \\
1993 & 40 & 39 & 0,97 & 20 & 18 & 20 & $\cdot$ & 38 \\
1994 & 40 & 30 & 0,75 & 13 & 12 & 15 & 2 & 29 \\
\hline
\end{tabular}

$\mathrm{v}_{\mathfrak{g}}$ - número de vagas ofertadas

Insc - inscriçöes recebidas para o curso no concurso vestibula

$C N$ - relação candidato/vaga

Apr - candidatos aprovados no concurso vestibular

Mat - candidatos aprovados que efetivaram matrícula

Rem - remanescentes

PD - portadores de Diploma de Curso Superior

Tot - Total de alunos da turma

Em 1992, o curso de biblioteconomia recebeu 28 inscrições ao concurso vestibular, ficando com uma relação candidato/vaga de 0,70 , pois foram oferecidas 40 vagas. Dos 28 inscritos, 12 foram aprovados e destes, apenas 9 matricularam-se, tendo recebido 24 alunos remanescentes, ficando com 33 matriculados. Os remanescentes são candidatos da mesma área que são aprovados no concurso vestibular, porém não classificados para seus respectivos cursos. Naquele ano os remanescentes vieram dos seguintes cursos: Administração noturno e matutino, Ciências Econômicas noturno, Comunicação Social - Jornalismo matutino, Comunicação Social - Relações Públicas matutino, Direito noturno, Educação Física matutino e noturno e Letras 
noturno. No ano de 1993, com 40 vagas e 39 inscritos, teve 0,97 candidato por vaga, sendo que 20 lograram aprovação e destes, 18 efetivaram matricula, tendo recebido 20 alunos remanescentes dos cursos de Ciências Contábeis noturno, Ciências Econômicas noturno, Comunicaçāo Social - Jornalismo matutino e noturno, Comunicação Social - Relaçōes Públicas matutino, Direito matutino e noturno, Geografia noturno e Letras vespertino.

A relação candidato/vaga em 1994 foi de 0,75 , pois com 40 vagas oferecidas, houve 30 inscritos, dos quais 13 aprovados e 12 matriculados. A esses somam-se 2 alunos que ingressaram como portadores de diploma de curso superior e 15 alunos remanescentes dos cursos de Administração matutino e noturno, Ciências Contábeis matutino, Direito matutino e noturno, Educação Física noturno, Filosofia noturno, Letras noturno, Secretariado Executivo noturno e Serviço Social noturno, resultando um total de 29 alunos.

A freqüência desses alunos nunca foi integral.

No começo do ano letivo eram 18 alunos, o que vem confirmar o observado por KREBS $(1988, p .16)$ de que "a evasão de alunos do curso de Biblioteconomia (da UEL) começa a ocorrer antes mesmo do início do curso". Em meados do mês de junho, quando foi realizado o presente estudo, freqüentando realmente as aulas, eram 15 alunos. Ou seja, 14 alunos ou $48 \%$ dos que ingressaram já haviam abandonado o curso em apenas três meses de aula. Fato este também confirmado no estudo de KREBS e pela literatura em geral, quando diz que o maior índice de evasão acontece nos períodos iniciais do curso, sendo que COSTA (1979) apud CARVALHO \& PEROTA (1990, p. 91), considera que "os altos índices de retenção e evasão nos primeiros semestres do ciclo básico são conseqüência do tipo de seleção promovido pelo concurso vestibular que forma um grupo heterogêneo que deve produzir homogeneamente. Isto é, realizar os estudos básicos de maneira uniforme, ao mesmo tempo e no mesmo nivel de profundidade."

A evasão no curso de Biblioteconomia da UEL no período de agosto/84 a dezembro/87, foi estudada por KREBS (1988), que constatou que no referido período $54 \%$ dos alunos evadiu-se, sendo a grande maioria no $1^{2}$ semestre do curso. As causas da evasão, apontadas pelos entrevistados ficam por conta de usar-se o curso como "trampolim" para transferências para outros cursos, em função da baixa concorrência no concurso vestibular.

No antigo regime de créditos, o aluno tinha a opção de transferência interna de curso. No atual regime inexiste esta possibilidade e a evasão persiste.

Neste mesmo período (1984-1987), ainda segundo KREBS (1988), os cursos de Biblioteconomia da Universidade Federal do Paraná e da Universidade de São Paulo, tiveram $28 \%$ e $45 \%$ de alunos evadidos, respectivamente.

No estudo de CARVALHO \& PEROTA (1990), quanto à evasão de alunos do curso de Biblioteconomia da Universidade Federal do Espírito Santo, onde $30 \%$ dos alunos evadiu-se no período de 1975 a 1984, as causas apontadas são incompatibilidade de horário e falta de motivação gerada pelo desconhecimento do que é
Biblioteconomia.

CESARINO et al. (1987), fez um estudo junto ao curso de Biblioteconomia da Universidade Federal de Minas Gerais, onde a evasāo em 1982/83 apresentou um índice de $33 \%$. A retenção, tema principal do estudo, apresentou um indice de $39 \%$ no ciclo profissional. A incompatibilidade de horário e a rigidez de currículo, aliado a uma baixa renda familiar e conseqüente necessidade de trabalhar para continuar no curso, são as causas apontadas para a retenção.

Apesar de ser uma das preocupações citadas a princípio, a alta taxa de evasão não é objeto deste estudo. Constitui-se, no entanto, em fator preponderante a ser estudado na busca de soluções para o problema levantado.

Os dados sobre escores obtidos nas provas do concurso vestibular, podem ser visualizados no Quadro 2 e mostram o desempenho do primeiro e último candidato aprovado, nas provas de Estudos Sociais (ESO), Português (PORT) e redação (RED). Os escores dos outros candidatos aprovados (menos o primeiro e 0 último), situam-se entre estes dois valores.

QUADRO 2

Esoores obtidos nas provas do Coneurso Vestibular polos candidatos ao Curso do Bibliotoconomia aprovados no período de 1992 a 1994

\begin{tabular}{|c|c|c|c|}
\hline \multirow{2}{*}{ Ano } & \multirow{2}{*}{ Provas } & \multicolumn{2}{|c|}{ Classlfleação } \\
\hline & & 18 & Último \\
\hline \multirow{4}{*}{1992} & ESO & 25 & 13 \\
\hline & PORT & 36 & 21 \\
\hline & RED . & 21. & . \\
\hline & ESO & 19 & 13 \\
\hline \multirow[t]{3}{*}{1993} & PORT & 30 & 18 \\
\hline & RED . & 24. & .04. \\
\hline & ESO & 23 & 16 \\
\hline \multirow[t]{2}{*}{1994} & PORT & 35 & 18 \\
\hline & RED & 40 & 14 \\
\hline
\end{tabular}

Os escores referem-se ao número de questões acertadas em cada prova e à pontuação obtida na prova de redação. Nestes concursos vestibulares a prova de Estudos Sociais constou de 40 questões e a de Português de 50 questões. Assim sendo, os candidatos que prestaram vestibular em 1992 apresentaram melhor desempenho nas provas de Estudos Sociais e Português e os que prestaram em 1994, um melhor desempenho na prova de redação.

FRANCO JUNIOR \& VASCONCELOS (1992, p. 6) consideram que "a prova de redação tornou-se, nos últimos anos, o grande desafio para os vestibulandos brasileiros e isso tem, entre as suas várias causas, uma razão óbvia: de modo geral, o trabalho de escrita e leitura não tem sido realizado de modo a preparar o aluno para o simples desafio que a prova do vestibular Ihe exige" e sugerem que no tocante ao ensino de primeiro, segundo e terceiro graus, deva ser priorizado os trabalhos com leitura e produção textual.

FRANCO \& BAETA (1985) trata a questão do vestibular através de revisão da literatura disponivel. Selecioram 4000 páginas distribuídas em 220 títulos, a maior parte produzida no eixo Rio-São Paulo e aborda os pontos seletividade social e democratização, além do aspecto 
económico-politico que permeia todo o sistema educacional, tendo seu reflexo nos exames vestibulares.

LESER (1985) lembra que até 1954, os candidatos a cursos superiores submetiam-se a provas escritas e prático-orais de fisica, quimica e biologia, cujos pontos eram sorteados no momento da prova, restringindo-se, por vezes, a uma única questão. Enumera os fatores alheios ao objeto do julgamento que interferiam no mesmo, tais como rapidez ou lentidão da escrita, grafia boa ou má e critério individual do examinador. Substituiu-se, em 1954 as provas escritas por provas de múltipla escolha e em 1955 foi acrescentado um teste de redação. Mais tarde discutiu-se a possibilidade de alguma diversidade quanto a ênfase a ser dada em algumas disciplinas segundo a destinaçāo dos candidatos para escolas com diferentes curriculos, bem como o direito de declaração de opções sucessivas, por ocasião da inscrição, a serem atendidas segundo a ordem de classificação nas provas. Conclui pela retomada da discussão da problemática dos vestibulares.

Para investigar o desempenho acadêmico dos alunos, levantou-se as médias aritméticas dos ingressantes de 1992 e 1993, que estão cursando atualmente o terceiro e o segundo ano do curso, respectivamente. Quanto aos que ingressaram em 1994 ainda não se dispõe de suas notas.

As médias aritméticas dos alunos do $3^{\circ}$ ano encontram-se entre 5,60 e 7,64 e as do $2^{\circ}$ ano entre 6,08 e 8,40 .

Levando-se em consideração que o regime seriado tem um sistema de aprovação que consta de exame final para os alunos que não alcançam média 7,0 e que a exigência para o exame é média 5,0 , isto é, se o aluno não alcançou média para aprovação sem o exame, fazse a média aritmética entre a nota do exame e a média anual e esta média deve ser no mínimo 5,0 para que ele seja considerado aprovado, decidiu-se levantar os alunos que tem média abaixo de 7,0 .

Atualmente o $3^{\circ}$ ano tem 15 alunos, dos quais 7 tem média abaixo de 7,0 . O $2^{\circ}$ ano tem 23 alunos e $6 \mathrm{com}$ média abaixo de 7,0.

Em termos numéricos, constata-se que dos 38 alunos com notas no curso ( $2^{\circ}$. e $3^{\circ}$ anos), $34 \%$ não alcancaram a média 7,0 , exigida para aprovaçāo. De forma geral este dado aponta uma melhora no desempenho dos alunos do regime seriado, podendo-se inferir, com grande margem de certeza que esta melhoria no desempenho, deve-se ao fato de que, no geral, o corpo discente, esforça-se exatamente o necessário para lograr aprovação. Quando a média requerida para aprovação era 5,0 , no antigo regime acadêmico semestral de crédito por disciplina, a maioria dos alunos tinha esta média. Hoje o esforço é para alcançar 7,0 que é a média de aprovação. Um dos alunos, ao sugerir mudanças para o curso, disse que a nota para aprovaçāo deveria voltar a ser 5,0. Uma das professoras ao justificar o desempenho de seus alunos, afirmou que eles se esforçam para obter a média de aprovação.

Para sondar a percepção que o aluno tem do curso, foi elaborado um questionário que investigou a procedência do aluno, o motivo da escolha do curso, a forma de ingresso, a pretensão de escolher outro curso, as dificuldades que enfrenta no curso, o apoio dispensado pelos professores, o rendimento, a satisfação com este rendimento, o conhecimento das funçōes exercidas pelo profissional bibliotecário, a percepção da preparação que o curso lhe proporciona para desempenhar estas funções e ainda solicitou-se sugestões de mudanças para o curso.

Este questionário foi aplicado ao universo do estudo, isto é todos os alunos do regime seriado anual, tendo sido respondido por um total de 44 alunos, sendo 13 do $1^{\circ}$ ano, 17 do $2^{\circ}$ e 14 do $3^{\circ}$.

Catorze alunos são provenientes de escola pública, 27 de escola particular, tendo sido impossivel identificar a procedência de três alunos.

Fizeram o segundo grau em Londrina 24 alunos, $6 \mathrm{em}$ outras cidades do Paraná e 14 em outros estados.

Quinze alunos fizeram "cursinho", 29 não.

Ao responder a questão "por que escolheu o curso de Biblioteconomia?", quatro alunos afirmaram tê-lo escoIhido por já trabalharem na área; 3 estão cursando para possuir um curso superior; 2 alunos porque possui bom mercado de trabalho; 4 afirmaram que o motivo foi pouca concorrência e 3 estão fazendo o curso por gostar de ler. Outros ainda responderam ter escolhido o curso para sistematizar a sua biblioteca; por gostar de restauração e documentos antigos; por ser um curso prático e porque interessou-se pela profissão. Muitos responderam simplesmente que entraram como remanescentes. Alguns responderam que a princípio "entraram por entrar" mas que começaram a gostar. Um aluno faz o curso por ser em Londrina, outro por ter paixão pelos livros. Um aluno afirma estar fazendo o curso por ter sido incentivado e outro por ter visto cartazes no Colégio onde cursava o $2^{\circ}$ grau.

O quadro 3 mostra a comparação entre o número de ingressantes através de vestibular e de vagas remanescentes com o número atual de alunos do curso.

QUADRO 3

Comparação entre o número de alunos ingressantes no período de 1992-1994 e o número atual de alunos no curso de Biblioteconomia

\begin{tabular}{|c|c|c|c|c|c|c|}
\hline \multirow{2}{*}{ ANO } & \multirow{2}{*}{\begin{tabular}{|c|} 
VES TIBULAR \\
para \\
Biblioleconomia \\
\end{tabular}} & \multirow{2}{*}{\multicolumn{2}{|c|}{\begin{tabular}{|c|c|}
\multicolumn{2}{|c|}{ Continuam no Curso } \\
TOTAL & $\%$ \\
\end{tabular}}} & \multirow[b]{2}{*}{ AEMAHESCENTES } & \multicolumn{2}{|c|}{ Continuam no Curso } \\
\hline & & & & & TOTAL & $\%$ \\
\hline 1992 & 9 & 6 & 66,6 & 24 & 7 & 29,2 \\
\hline 1993 & 18 & 9 & 50 & 20 & 8 & 40 \\
\hline 1994 & 12 & 6 & 50 & 15 & 8 & 53,3 \\
\hline TOTAL & 39 & 21 & 54 & 59 & 23 & 39 \\
\hline
\end{tabular}

Na composição da turma que ingressou em 1992, 9 alunos prestaram vestibular para o próprio curso. Atualmente 6 deles continuam no curso, representando $66,6 \%$. Como remanescentes, o curso recebeu 24 alunos, dos quais 7 continuam estudando, representando $29,2 \%$.

Em 1993 entraram 18 alunos através do concurso vestibular, sendo que 9 permanecem, representando $50 \%$ daquele total. Através de vagas remanescentes ingressaram 20 alunos, restando apenas 8 , o que representa $40 \%$.

Compôs a turma de 1994, 12 alunos que prestaram vestibular para o curso de Biblioteconomia, tendo continuado no curso 6 deles, o que representa $50 \%$ dos 
vestibulandos. Neste ano 15 alunos ingressaram como remanescentes de outros cursos e 8 deles continuam no curso, representando $39 \%$ do total.

Pode se concluir então que dos 39 alunos que ingressaram no curso prestando vestibular para o próprio curso, 21 continuam no curso, representando $54 \%$ do total. Dos 59 alunos que ingressaram como remanescentes, 23 continuam no curso, representando $39 \%$. Ou seja, dos alunos que tiveram como primeira opção o curso, $53 \%$ continuam preferindo-o e dos alunos que entraram no curso por não terem conseguido entrar no curso de sua preferência, apenas $39 \%$ mantiveram sua $2^{2}$ preferência. É interessante observar que o número de alunos que tiveram por primeira preferência outro curso sempre foi maior, apesar de terem se evadido em maior proporção.

Trinta e oito alunos responderam negativamente a questão "você tentou ou pretende tentar outro vestibular enquanto estiver fazendo este curso?". Dos seis que deram resposta positiva, um observou "após a conclusão deste".

Quando indagados sobre as maiores dificuldades encontradas no curso e as formas de resolvê-las, a maloria dos alunos apontou como dificuldade maior a falta de tempo para estudar, seguida da dificuldade de conciliar horário de trabalho e estudo e ainda a dificuldade com as disciplinas técnicas.

Um respondente apontou a falta de hábito de leitura como dificuldade. Concordam que para resolverem o maior problema, falta de tempo, precisam "estudar mais". Alguns contam com apoio de amigos, outros estudam nos pequenos intervalos e outros pedem explicação aos professores, para resolverem seus problemas.

Ao responderem sobre o apoio recebido por parte dos professores, 37 alunos disseram encontrar apoio, 3 responderam que não, 3 deixaram em branco e 1 disse que "alguns professores são acessiveis, outros, nem tanto". A maioria das justificativas a esta questão seguiram o padrão de que os professores sempre atendem bem, explicam novamente, estão prontos a esclarecer, tanto no horário de aula como fora dele, são bons profissionais. Algumas respostas, no entanto, apontaram que o apoio não é total por parte de alguns professores e que são amigos, mas há exceçōes.

A questão que tentou investigar o rendimento em termos de notas dos alunos, apresentou um erro estrutural, o que impossibilitou o seu confronto com as médias aritméticas levantadas junto à CAE - Coordenadoria de Assuntos de Ensino de Graduação.

Nenhum aluno respondeu que as médias de suas notas encontravam-se entre 1,0 e 3,0 e nem acima de 9,0 . Um aluno classificou sua performance entre 3,1 e 5,0 , dezenove entre 5,1 e 7,0 e vinte e quatro entre 7,1 e 9,0 .

Quanto a satisfação com seu desempenho, dezoito alunos estão satisfeitos, vinte e quatro não estão e dois se furtaram a responder. As justificativas para as respostas positivas são de que as notas têm sido razoáveis, está bom, mas pode melhorar, que o desempenho quando comparado com outros é bom, que aproveita bem o tempo e que possui bagagem. Para as respostas negativas as justificativas são de que nunca foi tão mal; por motivos pessoais; falta de tempo; dificuldade de con- ciliar as várias atividades; falta de aprofundamento; e falta de dedicação. Quando indagados sobre "o que têm feito para melhorar este desempenho" as respostas ficaram por conta de que "está organizando melhor o horário", "procurando desempenhar melhor", "ler mais". Cinco alunos disseram que têm estudado mais, dois têm feito mais leituras, um aluno afirmou que por enquanto não fez nada, mas que pretende fazer, outro considera que deve levar o curso mais a sério e três responderam que tentam esforçar-se mais.

Responderam afirmativamente quando indagados se têm conhecimento das funções que um bibliotecário exerce, trinta e oito alunos, um respondeu que vagamente, um disse não saber e quatro deixaram em branco. Ao especificar as funções, seis alunos deixaram em branco, nove responderam as funções globais que fogem das atividades de rotina do profissional bibliotecário, mas a grande maioria percebe as funções estanques, vinculadas às atividades de rotina.

Trinta e um alunos acreditam que o curso os tem preparado para desempenhar as funções de um bibliotecário, um considera que é cedo para opinar, outro sente-se perdido, um terceiro acredita haver nova visão dos responsáveis para incluir as novidades e preparar meIhor. Seis alunos afirmaram que o curso não prepara para - exercício da profissão e dois não opinaram. Quando solicitados a justificarem suas respostas, três alunos disseram faltar prática, dois que as aulas práticas deixam a desejar, um acredita que está despreparado para trabalhar fora de uma biblioteca, dois alunos dizem que o curso não prepara para as funções não relacionadas à biblioteca. Em contrapartida, acreditam que o curso ensina a pesquisar; dá um bom embasamento; que através dos estágios a preparação é melhor; e que prepara muito bem. Um aluno acredita que a faculdade dá apenas a base. Três alunos deixaram de justificar sua resposta.

Doze alunos não sugeriram mudança alguma no curso, dois se furtaram a responder e os outros trinta sugeriram o seguinte: "ter mais aulas práticas" (3), "visitar mais bibliotecas, além da Biblioteca Central" (3), "que o curso fosse mais perto da biblioteca" (1), "que tivesse mais matérias básicas" (1), "maior divulgação profissional" (1), "mudar o nome do curso" (4), "atualização do material fornecido pelos docentes" (2), "divulgar aos alunos de outros cursos, a importância deste" (1), "maior relacionamento com a Biblioteca Central" (1), "aumentar a carga horária de algumas disciplinas" (1), "diversificar as matérias para não "bitolar" na biblioteca" (1), "reformulação de currículo" (1), "que preparassem os bibliotecários para serem cientistas" (1), "que voltasse a ser média 5,0" (1), "que houvesse mais eventos" (2), "que a disciplina de Filosofia fosse voltada para a biblioteconomia" (1), "mais matérias específicas" (2), "menos matérias de outros cursos" (2), "não deveria ter quatro aulas com a mesma professora num mesmo dia" (1), "que os estágios começassem no $1^{\circ}$ ano" (1), "empenho maior por parte de alguns professores" (1), "meIhor distribuição das aulas" (1), "criar troncos: biblioteconomia para biblioteca, para indústria" (1), "trazer para o curso a disciplina de "marketing" (1), "automação desde o $1^{\circ}$ ano" (1), "estudo da questão da leitura escolar e social" (1), "maior agilidade" (1) e "mai- 
or aprofundamento" (1).

Elaborou-se um questionário que foi aplicado às professoras que ministram aulas aos alunos do regime seriado, com o objetivo de investigar a percepção das mesmas no que tange ao desempenho dos alunos; à atribuição deste desempenho; relação entre o vestibular para o curso e o atual desempenho; fatores relevantes que o aluno deve possuir para um bom desempenho profissional; a presença destes fatores em seus alunos e a sua contribuição para que eles os adquiram. Investigou ainda como a docente percebe a contribuição de sua disciplina para a formação do bibliotecário e o que o curso tem oferecido para formar um bom profissional.

Onze professoras trabalham com alunos do regime seriado. A autora deste estudo não respondeu para evitar o duplo papel de pesquisadora/pesquisada. Os instrumentos foram entregues pessoalmente para dez professoras, sendo que nove foram devolvidos respondidos, dentro do prazo solicitado, o que denota a disposição do corpo docente em contribuir.

Ao serem interrogadas sobre o desempenho dos alunos nas disciplinas que ministram, duas professoras categorizaram também as turmas anteriores e mesmo dentro de uma única turma houve mais de uma categorização, motivo pelo qual na tabulação aparecem mais respostas que número de respondentes. Houve uma pontuação para "excelente", cinco para "bom", oito para "regular" e um para "insuficiente".

As professoras atribuem o desempenho regular, que a maioria dos alunos apresenta, em primeiro lugar à falta de interesse pelo curso, pois houve a incidência de seis respostas neste fator. Em segundo lugar à falta de interesse pelos conteúdos das disciplinas e em conhecer as atividades. Listam ainda falta de pré-requisitos; falta de cultura geral; falta de vontade de estudar; falta de participação; falta de discussão; falta de espírito crítico; falta de espírito universitário; desmotivação; desânimo; culpa do corpo docente e educação formal anterior; como causas do fraco desempenho do corpo discente. Uma professora disse que seus alunos interessam-se por aprender conteúdos técnicos e outra que eles estudam para obtenção da média de aprovação.

Cinco professoras acreditam que existe relação entre o vestibular e o atual desempenho dos alunos; três não vêem relação e uma afirma que "as vezes". As justificativas são as seguintes: o preparo para o vestibular propicia um melhor perfil e desempenho; quando o nivel é baixo no $2^{\circ}$ grau, no $3^{\circ}$ grau também é; os alunos que prestaram vestibular para o curso de Biblioteconomia interessam-se mais; a baixa concorrência para o curso prejudica; très professoras acreditam que a exigência de bagagem cultural diminui à medida que diminui a procura pelo curso; que o desempenho do aluno reflete e constata a realidade do ensino de $1^{\circ}$ e $2^{\circ}$ graus; que existe imaturidade e dificuldade de verbalização por parte dos alunos e que o vestibular não seleciona, é uma questão de sorte.

O grau de importancia que o corpo docente atribui, para um bom desempenho do profissional bibliotecário, aos fatores bagagem cultural, bom desempenho na graduação, constante atualização, capacidade de leitura crítica, fluência e correção na redação e na linguagem, é mostrado no Quadro 4.
Solicitadas a numerar por ordem de importância os fatores que consideram relevantes para um bom desempenho do profissional bibliotecário, a docente 1 enumerou somente até o $4^{\circ}$ item mais importante, as demais numeraram todos os itens, colocando, porém o mesmo número a mais de um fator, o que representa que ela atribui o mesmo grau de importância aos dois fatores. Em função da numeração ter sido solicitada por ordem de importância, atente-se para o detalhe de que quanto menor a pontuação atribuída a determinado fator, mais importante ele se coloca no cômputo geral e quanto maior esta pontuação menos importância ele tem.

Algumas professoras acrescentaram os seguintes fatores com pontuação: gosto pelo curso (5); criatividade (5); capacidade de decisão (4); e conhecer o desempenho de um profissional (1).

Estes fatores foram acrescentados àqueles, sendo numerados de acordo com o grau de importância que cada respondente atribuiu aos mesmos. Desta forma, na tabulação dos dados aparecem graus de importância acima do número seis, que foi o número de fatores considerados ou apresentados para julgamento.

Foram acrescentados ainda, sem pontuação, "criatividade", "espírito de liderança" e "inovação", como fatores relevantes na formação de um bom profissional.

Como fatores relevantes apontados pelas docentes, pode-se considerar, "capacidade de leitura crítica" em primeiro lugar e "bagagem cultural" e "constante atualização em segundo lugar. Ocupa a terceira posição de importância entre as professoras "bom desempenho na graduação". "Fluência e correção na redação" e "na linguagem" foram apontados como fatores de última importância para um bom desempenho profissional, conforme se observa no Quadro 4, pois, quanto menor a média apresentada pelo fator, significa que mais importante seja considerado aquele item para o corpo docente, para um bom desempenho do profissional bibliotecário.

\section{QUADRO 4}

Fatores que na opinião do corpo docente são nelevantes para um bom desempenho do profissional bibliotecário

\begin{tabular}{|c|c|c|c|c|c|c|c|c|c|c|}
\hline \multirow[t]{2}{*}{ Fatores considerados } & \multicolumn{9}{|c|}{$\frac{\text { Grau de Importåncla }}{\text { Docente }}$} & \multirow[t]{2}{*}{ Média } \\
\hline & 1 & 23 & & & & & 78 & & & \\
\hline Bagagem cuttural & 2 & 42 & 2 & 3 & 3 & 3 & 1 & 2 & & 2,7 \\
\hline Bom desempenho na graduaçâo & 1 & 7 & 6 & 7 & 4 & 6 & 4 & 1 & 1 & 4,1 \\
\hline Constante atualização & 4 & 6 & 1 & 2 & 2 & 2 & 3 & 2 & 2 & 2,7 \\
\hline Capac. do bltura critica & 3 & 1 & 3 & 4 & 1 & 1 & 2 & 3 & 3 & 2,3 \\
\hline Fluêncla correçảo na redação & & 3 & 4 & 5 & 3 & 8 & 6 & 3 & 5 & 4,6 \\
\hline Fluêncla - correçäo na IInguagam & & 2 & 8 & 6 & 3 & 7 & 5 & 3 & 6 & 4,6 \\
\hline
\end{tabular}

Pode-se afirmar com certeza, com base nestes dados, que o corpo docente acredita que o fator preponderante para um bom desempenho profissional seja a capacidade de leitura crítica ; pois três professoras o colocaram em primeiro lugar, uma em segundo, quatro em terceiro e uma em quarto lugar, resultando como média 2,3 entre os fatores investigados. Bastante próximo de 1,0 que representaria a valorização mais alta possivel do referido fator na formação profissional.

Em relação a estes fatores, considerados como mais importantes na formação profissional, as professoras percebem que seus alunos apresentam-se razoáveis 
nhecimento é obtido através da observação e da experiência.

No $1^{\circ} \mathrm{grau}$, ela encontra-se inserida na disciplina Ciências Físicas e Biológicas.

No $2^{\circ}$ grau, a disciplina aparece com a denominação de Biologia.

Ao longo do tempo, o ensino dessas disciplinas vem sofrendo modificações constantes, tanto no que se refere ao currículo, quanto ao conteúdo e metodologia, no sentido de se substituir os métodos tradicionais, onde as informações são passadas pelo professor, repetidas e memorizadas pelo aluno.

Em anos anteriores, o objetivo do programa oficial era o de formar profissionais para atuarem no ensino superior e preparar futuros cientistas. No entanto isso era feito sem uma evidente relação prática, social e política.

No Brasil, muitos debates têm ocorrido, destacando o papel dos anos 60 , na mudança do ensino de Ciências. A preocupação era aproximar o ensino-aprendizagem em Ciências com o trabalho científico, superando a pura transmissão de conteúdos. Passou-se então a acreditar na aprendizagem por descoberta ou redescoberta. De 60 a 70 , o objetivo do programa oficial passou a ser a vivência do método científico para a formação do cidadão. A preocupação era com a participação do aluno e a manipulação de equipamentos. Mesmo assim, no sistema educacional prevalecia a memorização, especialmente para os Vestibulares.

De 70 a 80 , ocorreu uma expansão das metas do ensino de Ciências, devido às mudanças sociais e às agressões ao meio ambiente. Houve necessidade de se adquirir nova postura em relação à Ciência. $O$ objetivo passou a ser o aluno discutindo as implicações sociais no desenvolvimento científico. Nessa época surgiu a Lei no 5.692/71 (Brasil, 1971) que fixou as diretrizes e bases da escola de $1^{\circ}$ e $2^{\circ}$ graus, introduzindo os cursos profissionalizantes, com os seguintes objetivos:

\section{"O ensino de $1^{\circ}$ e $2^{\circ}$ graus tem por obje- tivo geral proporcionar, ao educando, a formação necessária ao desenvolvimen- to de suas potencialidades como ele- mento de auto-realização, qualificação para o trabalho e preparo para o exerci- cio consciente da cidadania". (Art. 1, da Lei $n^{\circ}$ 5692/71).}

Inserida no currículo, a Biologia deve visar a compreensão da realidade, buscando a melhoria da qualidade de vida. Os tópicos devem estar integrados e a linguagem do professor deve ser adequada com o objetivo de desenvolver o espírito de análise, de crítica e de transferência do aprendido. Para tanto, é importante a formação acadêmica do professor. Este deve ter, não só conhecimento do conteúdo, como também deve utilizar práticas e técnicas simples de modo a despertar o espírito científico nos seus alunos. Estariam assim atingindo os objetivos do ensino de Ciências, previstos na Resolução no 8/71 e no Parecer 835/71 (Brasil, 1971) do Conselho Federal de Educação: "Desenvolver o pensamento lógico e a vivência do método científico, sem deixar de pôr em relevo as tecnologias que resultam de suas aplicações".
"Em qualquer tentativa de estudo dos problemas e das soluções do ensino de Ciências, duas situaçôes devem ser analisadas: a situação aparente e a situação real desse ensino". (HENNING, 1986, p.24)

Henning chama de situação aparente os aspectos positivos que deveriam promover uma boa aprendizagem. Aspectos estes com base na legislação em vigor Lei n 5692/71 (Brasil, 1971) e Lei n 7044/82 (Brasil, 1982), nos objetivos do ensino de Ciências; Resolução no 8/71 e Parecer $n \circ 835 / 71$ (Brasil, 1971, apud Henning, 1986 , p.62), nas técnicas de ensino, na tecnologia educacional, na qualificação dos professores e no direcionamento que se dá ao ensino de Ciências.

A Lei $n^{\circ} 7.044 / 82$ modifica o Art. $1^{2}$ da Lei $n^{\circ} 5692$ 71 , substituindo a expressão qualificação para o trabatho por preparação para o trabalho.

Por outro lado, HENNING (1986) denomina de situação real aos aspectos negativos indicadores de que a aprendizagem não está possibilitando a aplicação de métodos, produzindo conhecimentos para a vida, desenvolvendo criatividade, promovendo a confiança para a integração na comunidade.

Do desacerto entre situação real e aparente vem como conseqüência provável: um ensino formal, discursivo, com práticas irrelevantes, didática superada, metodologia inadequada, currículos impróprios, etc.

A Biologia é uma ciência que estuda os seres vivos, a relação entre eles e o meio ambiente, além dos processos e mecanismos que regulam a vida. Portanto, todo e qualquer problema que envolva conhecimentos da natureza viva, deve ser tratado pelos profissionais formados em Ciências Biológicas.

Além da formação acadêmica, deve-se levar em consideração as condições de trabalho do professor como: laboratórios, programas, horário de trabalho, currículo, etc., para que o ensino de Ciências possa colaborar com a real formação do aluno, principalmente instigando-o à investigação e à reflexão.

O professor de Biologia é muitas vezes substituido por diferentes profissionais: agrônomos, veterinários, médicos, zootecnistas, bioquímicos e outros. Embora possa parecer que haja superposição de atribuições, isto é apenas aparente, pois, o enfoque que cada um desses profissionais tem do campo biológico é característico e próprio de sua formação; além do problema da falta de uma metodologia de ensino adequada.

Os rumos da sociedade evoluem de forma dinâmica e complexa e seu desenvolvimento ocorre por ação e transformação da natureza pelo homem. Uma vez que - professor de Ciências Biológicas estuda a natureza viva tanto para poder transmitir conhecimentos como para poder apontar soluções para os problemas causados por modificações dessa natureza, é importante que esse profissional encare a Biologia como uma Ciência não desvinculada da realidade social. Assim, poderá praticar uma Biologia que sirva ao desenvolvimento sóciocultural do homem integrado à natureza, não só no campo da pesquisa como também no campo do ensino.

Analisando a nova proposta para o ensino de $\mathrm{Ci}$ ências do Paraná, contida no Currículo Básico para a Escola Pública do Estado do Paraná (SECRETARIA DE 
BARTALO, Linete. Academic achievement of the Librarianship Course at Londrina State University. Semina: Ci. Soc./Hum., Londrina, v. 16. n. 2., Ed.Especial, p.27-35, out. 1995.

ABSTRACT : Some aspects concerning the Librarianship Course at the State University of Londrina were analysed concerning demand for the course, success in the entrance examination, remainders from other courses attending the Librarianship Course, academic achievement, students'awareness of the course and teachers'awareness of the academic achievement in the last three years. The data are analysed and some solution hypothesis are suggested in order to broaden the studies of the course evaluation, as well as to divulge Ihe Librarian profession and also to build up programs that discuss the difficulties found in the background formation which consequently are reflected in the academic achievement. The need for a subject on reading in the curriculum is emphatized not only for the Librarianship Course but also for the other courses at UEL, since the ability to critical reading was pointed out as preponderant in the background formation of the sdudents. The possibility of an immediate application of the solution hypothesis suggested are previewed.

KEY - WORDS: Library Science - academic achievement; Library Science - academic formation; Library Science Students outline.

\section{REFERÊNCIAS BIBLIOGRÁFICAS}

BORDENAVE, J. D. ; PEREIRA, A. M. Estratégias de ensino apren dizagem. 4. ed., Petrópolis : Vozes, 1982.

CARVALHO, I. C. L. ; PEROTA, M. L. L. A evasão dos alunos do curso de biblioteconomia da Universidade Federal do Espírito Santo. R. Bibliotecon. \& Comun., Porto Alegre, v. 5, p. 88 - 97 , jan./dez. 1990.

CESARINO, M.A. da N. et. al. A retenção de alunos por infrequência : aproveitamento e trancamento de matrícula no curso de graduaçáo em blblioteconomia da Universidade Federal de Minas Gerais. R. Esc. Bibliotecon. UFMG., Belo Horizonte, v. 16, n. 2 , p. $159-190$, set. 1987.

FERRACIN, A. M. ; PIMENTEL, C.D.P. Relatório final do seminário: "o curso de blblioteconomia em debate". Cad. Bibliotecon. Recife, n. 11, p. 63-81, dez. 1989.

FRANCO, M. A. C. Acesso à Universidade : uma questão política e um problema motodológico. Educação e Seleção, São Paulo, Fundação Carlos Chagas, v. 7, p. 9 - 26, jul./dez. 1985

FRANCO, M. A. C. ; BAETA, A. M. B. Quinze anos de vestibular (1968 a 1983) : apresentação. Educação e Seleção, São Paulo, Fundação Carlos Chagas, v. 7, p. 3 - 8, jul./dez. 1985.
FRANCO JUNIOR, A. ; VASCONCELOS, S. Redação do vestibular : o grande desafio é a leitura. Universidade e Sociedade, UEM, Maringá, n. 12, p. 5 - 8, abr. 1992.

KLEIMAN, A. B. Diagnóstico de dificuldades na leitura : uma proposta de instrumento. Cadernos PUC Lingüistica. São Paulo : EDUC, n. 16, p.34 - 50, 1983.

KREBS, L. I. Levantamento do índice e causas de evasão dos alunos do curso de biblioteconomia da Universidade Estadual de Londrina, no período de agosto/84 a dezembro/87. Londrina, 1988. 29 fls. Monografia (Graduação em biblioteconomia) - Departamento de Biblioteconomia, Universidade Estadual de Londrina

LESER, W. S. P. As origens do vestibular unificado. Educação $e$ Seleção, São Paulo, Fundação Carlos Chagas, n. 11, p. 3 - 7, jan./ jun. 1985.

MATOS, F. G. de. Implicações pedagógicas de idéias psicolinguísticas sobre leitura. Cadernos PUC Lingüistica, São Paulo: EDUC, n. 16, p. 51 - 58, 1983.

UNIVERSIDADE ESTADUAL DE LONDRINA. Coordenadoria de Assuntos de Ensino de Graduação. Proposta curricular do curso de biblioteconomia. (mimeogr.) 